\title{
ENERGETICS OF TERRESTRIAL LOCOMOTION OF THE PLATYPUS ORNITHORHYNCHUS ANATINUS
}

\author{
F. E. FISH ${ }^{1, *}$, P. B. FRAPPELL ${ }^{2}$, R. V. BAUDINETTE ${ }^{3}$ AND P. M. MACFARLANE ${ }^{2}$ \\ ${ }^{1}$ Department of Biology, West Chester University, West Chester, PA 19383, USA, ${ }^{2}$ Department of Zoology, \\ La Trobe University, Melbourne, Victoria 3083, Australia and ${ }^{3}$ Department of Environmental Biology, \\ University of Adelaide, Adelaide 5005, Australia \\ *e-mail: ffish@wcupa.edu
}

Accepted 6 December 2000; published on WWW 1 February 2001

\begin{abstract}
Summary
The platypus Ornithorhynchus anatinus Shaw displays specializations in its limb structure for swimming that could negatively affect its terrestrial locomotion. Platypuses walked on a treadmill at speeds of $0.19-1.08 \mathrm{~m} \mathrm{~s}^{-1}$. Video recordings were used for gait analysis, and the metabolic rate of terrestrial locomotion was studied by measuring oxygen consumption. Platypuses used walking gaits (duty factor $>0.50$ ) with a sprawled stance. To limit any potential interference from

result of the relatively low standard metabolic rate of this monotreme. The dimensionless cost of transport decreased with increasing speed to a minimum of 0.79 . Compared with the cost of transport for swimming, the metabolic cost for terrestrial locomotion was 2.1 times greater. This difference suggests that the platypus may pay a price in terrestrial locomotion by being more aquatically adapted than other semi-aquatic or terrestrial mammals.
\end{abstract} the extensive webbing on the forefeet, platypuses walk on their knuckles. Metabolic rate increased linearly over a 2.4-fold range with increasing walking speed in a manner similar to that of terrestrial mammals, but was low as a
Key words: platypus, Ornithorhynchus anatinus, walking, energetics, cost of transport, gait, locomotion.

\section{Introduction}

The evolution of semi-aquatic mammals from terrestrial ancestors has occurred several times in the mammalian clade. With increased aquatic habits, morphological and physiological changes have adapted animals to operate on land and in water. Fish (Fish, 1992) has previously commented on the compromises inherent in moving between these two media. Adaptations for swimming by semi-aquatic mammals (e.g. increased body size, increased bone density, elongation of the foot with increased area from inter-digital webbing, increased mechanical advantage) are antithetical to rapid and economical movement on land. It is suggested that semi-aquatic mammals may display increased energetic costs during terrestrial locomotion (Fish, 1992; Fish and Baudinette, 1999). Unfortunately, there are few direct comparisons between terrestrial and aquatic locomotory performance. In one such study on the semi-aquatic Australian water rat Hydromys chrysogaster, Fish and Baudinette (Fish and Baudinette, 1999) suggested that the energy costs of terrestrial locomotion and swimming were both high compared with those of specialists and that this extra cost may result from difficulties in specialising in either environment. Furthermore, more aquatically adapted organisms would be affected negatively in their energetic performance on land as the energetics of swimming becomes more efficient.
The platypus Ornithorhynchus anatinus Shaw is semiaquatic in its habits but has features of a highly specialised swimmer. Fish et al. (Fish et al., 1997) confirmed earlier observations (Howell, 1937) that the animal swims by alternate rowing motions of the forelimbs, the only mammal to adopt this swimming gait. They also showed that the cost of transport and metabolic rate were lower than in semi-aquatic mammals that use a paddling mode of propulsion. This, together with morphological features such as fine fur to insulate the body in water (Grant and Dawson, 1978), broad webbed feet and a compressed tail, suggests a move towards aquatic specialisation.

The platypus forages in water, and its life cycle is tied to burrows constructed in the banks of streams. However, the animals are frequently seen moving overland and are known to climb steep slopes in moving between lakes (Grant, 1989). Cineradiographic analysis of the animal during walking shows substantial long-axis rotation of the humerus, thus twisting the antebrachium over the positioned manus. This pattern is repeated in the two other genera of monotremes, the echidnas (Pridmore, 1985). However, as first pointed out by Burrell (Burrell, 1927), the major difference between the three is that the platypus is a 'knuckle walker' with the manus distally flexed on contact with the substratum. 
The purpose of this study was to examine the energetics of terrestrial locomotion in the platypus and to relate this to characteristics of the gait cycle. The animals readily walked on a treadmill at a range of speeds, and metabolic rates were measured using a novel technique that avoided the use of an attached mask. Comparison of locomotor efficiency with that of aquatic and terrestrial specialists is through a dimensionless variable, the cost of transport.

\section{Materials and methods} Animals

Six adult platypus Ornithorhynchus anatinus Shaw, four males and two females, were taken from creeks near the town of Eildon in northeastern Victoria, Australia. The mass of the animals ranged from 0.984 to $2.230 \mathrm{~kg}$, with a mean value of $1.395 \pm 0.438 \mathrm{~kg}$ (mean \pm S.E.M.). They were netted in Fyke nets under permit from the State Department Natural Resources and Environment. Platypuses are prone to a marked adrenocortical response following capture (McDonald et al., 1992) and, under the conditions of the permit, were returned to the site of capture within $6 \mathrm{~h}$. This meant that the animals could not be subjected to a training regime prior to the experiments being performed. All experiments were conducted in a darkened room, at an ambient temperature close to $20^{\circ} \mathrm{C}$, between $22: 00$ and 04:00 $\mathrm{h}$. This encompassed the normal activity periods of the animals. Each animal was walked at four speeds with a $30-60 \mathrm{~min}$ period of recovery between tests. Even in the absence of training, the animals readily walked on a motorised treadmill belt $(0.4 \mathrm{~m}$ wide and $2 \mathrm{~m}$ in length) and could maintain position to match the belt speed.

\section{Metabolic measurements}

Measurements of oxygen consumption were made from the fractional oxygen and carbon dioxide concentrations of air drawn from a mask that formed part of an open-circuit system. The mask was formed from light plastic and was transparent, ensuring a clear visual field for the animal. The end of the treadmill was also transparent. The mask approximated the shape of the head and, rather than being fitted to the animal, was connected at right angles to a length of clear Perspex tubing, $125 \mathrm{~cm}$ long, positioned over the head within the effective sampling zone of the system while the animal walked. Nitrogen gas metered into the collecting zone of the mask indicated no leakage or loss of expired gas. Further details of this approach are presented by Baudinette et al. (Baudinette et al., 1992).

Room air was drawn through the mask at flow rates of $351 \mathrm{~min}^{-1}$ using a pump (40W Reciprotar AB, type 506). The flow was measured by a mass flow controller (Sierra Instruments, model $840 \mathrm{M} 2$ ). A subsample of the gas was drawn at $400 \mathrm{ml} \mathrm{min}^{-1}$ through a drying column of Drierite $\left(\mathrm{CaSO}_{4}\right)$ and then to oxygen and carbon dioxide analysers (AD Instruments, ML205 gas analysers). The output from the analysers and the speed of the treadmill were recorded using a data-acquisition system (AD Instruments, Powerlab 800) collecting data at $10 \mathrm{~Hz}$. Oxygen consumption was calculated after overcoming errors related to respiratory quotient (RQ; Frappell et al., 1991; Appendix within) and correcting the flow through the mask for water vapour (measured using the $\mathrm{O}_{2}$ analyser with and without a drying column). The data reported are considered to be steady-state measurements (RQ averaged 1.0) showing less than $5 \%$ variation over the recorded period; each run lasted $15-70 \mathrm{~s}$. The time required to reach equilibrium for the complete system following a pulsed perturbation in the mask was $6 \mathrm{~s}$.

The resting rates of oxygen consumption could not be measured because the animals would not remain motionless.

The rate of oxygen consumption at STPD, representing metabolic rate, was converted to energy units assuming that $20.1 \mathrm{~J}$ is equivalent to $1 \mathrm{ml}$ of $\mathrm{O}_{2}$. The cost of transport $(C O T)$, the metabolic cost to move a unit mass over a given distance (Tucker, 1970; Videler and Nolet, 1990), was calculated as:

$$
C O T=M R / M \mathrm{~b} g U,
$$

where $C O T$ has units of $\mathrm{J} \mathrm{N}^{-1} \mathrm{~m}^{-1}, M R$ is the metabolic rate in $\mathrm{J} \mathrm{s}^{-1}, M_{\mathrm{b}}$ is the body mass in $\mathrm{kg}, \boldsymbol{g}$ is the acceleration constant of $9.8 \mathrm{~m} \mathrm{~s}^{-2}$ and $U$ is the velocity at which the animal walked in $\mathrm{m} \mathrm{s}^{-1}$.

\section{Determination of stride frequency and gait}

Gait analysis and step frequency were determined from video recordings (Panasonic camcorder, model PV-5100) made at $60 \mathrm{~Hz}$. The filming was conducted during each metabolic experiment, usually for approximately $20 \%$ of the total time. Sequential frames of video tape $(1 / 30 \mathrm{~s})$ were viewed using a Panasonic AG-7300 video recorder and Panasonic CTJ-2042R monitor. Video recordings were chosen for analysis only if the animal moved continuously so that its speed matched the belt speed on the treadmill. Gaits were determined following Hildebrand (Hildebrand, 1980). Step frequency was determined from the inverse of the period of a complete limb cycle, averaged over five cycles.

\section{Statistical treatment}

Individual platypuses were tested multiple times over a range of velocities, so statistical tests were made using analysis of variance (ANOVA) with individual $(N=6)$ as a random factor and velocity as a covariate. Statistical testing was performed using STATISTICA for the Macintosh (Version 4.1; StatSoft, Tulsa, OK, USA). Regression equations were determined using KaleidaGraph (Synergy Software, Reading, PA, USA).

\section{Results \\ Locomotor movements}

During locomotion on the treadmill, the platypus was capable of moving over a range of speeds from 0.19 to $1.08 \mathrm{~m} \mathrm{~s}^{-1}$. The only gait used by the platypus was a walk; the frequency $(f)$ of the stride cycle increased linearly with increasing speed $(U)$ (Fig. 1; Table 1; $t=11.13 ; P<0.001$ ). The 


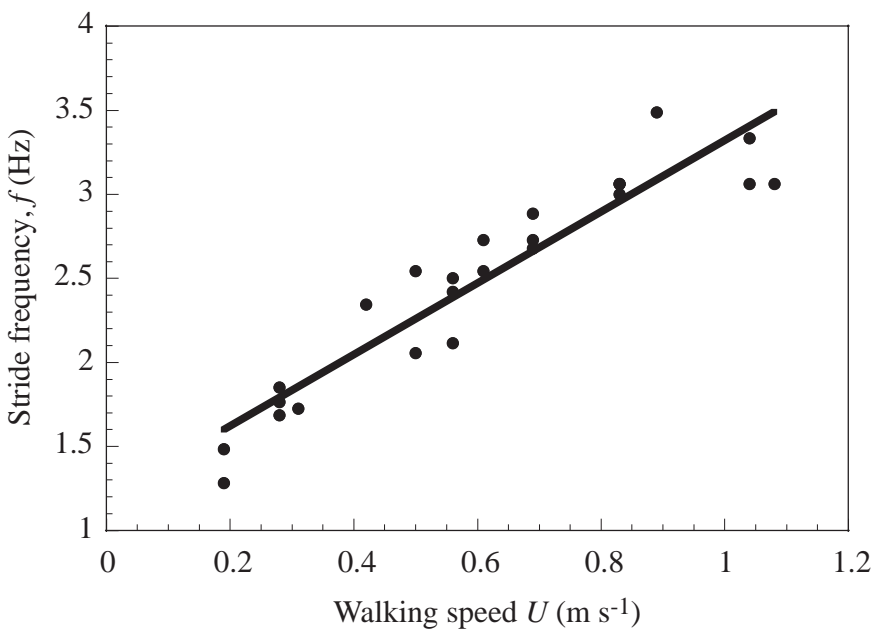

Fig. 1. Stride frequency $(f)$ as a function of walking speed $(U)$ for platypuses. The line was fitted by least-squares regression according to equation 2 in the text.

linear equation describing the relationship between frequency (in $\mathrm{Hz}$ ) and speed in $\left(\mathrm{m} \mathrm{s}^{-1}\right)$ is:

$$
f=1.19+2.13 U \text {. }
$$

The gait changed from a slow walk with a single foot in lateral sequence to a fast walk in which the animals employed a diagonal couplet in a lateral sequence (Hildebrand, 1980). This is reflected in the significant linear relationship between the percentage of time that the forefoot follows an ipsilateral hindfoot movement $\left(P T_{\mathrm{f}-\mathrm{h}}\right)$ and $U$ (Fig. 2; Table 1; $t=2.19$; $P<0.04)$ according to the equation:

$$
P T_{\mathrm{f}-\mathrm{h}}=36.64+8.50 U \text {. }
$$

There were always two feet on the ground at any time, with
Table 1. F-values from ANOVAs performed on each kinematic and physiological variable of terrestrially locomoting

\begin{tabular}{|c|c|c|c|}
\hline Dependent variable & $\begin{array}{c}F \text {-value } \\
\text { for velocity }\end{array}$ & d.f. & $P$-value \\
\hline Frequency & 123.85 & 1,17 & $<0.001$ \\
\hline Duty factor & 4.75 & 1,17 & $<0.044$ \\
\hline$P T_{\mathrm{f}-\mathrm{h}}$ & 4.80 & 1,17 & $<0.043$ \\
\hline Metabolic rate & 13.18 & 1,14 & $<0.003$ \\
\hline Cost of transport & 15.41 & 1,14 & $<0.002$ \\
\hline
\end{tabular}
platypus

$P T_{\mathrm{f}-\mathrm{h}}$, the percentage of time that the forefoot follows an ipsilateral foot movement.

periods during which three feet contacted the ground (Fig. 3). The percentage of the cycle that an individual foot was in contact with the ground (duty factor) decreased with increasing $U$ but never reached the levels of $50 \%$ indicative of a running gait (Fig. 2). The duty factor $D$ increased linearly with increasing $U$ (Table $1 ; t=-2.18 ; P<0.04$ ):

$$
D=65.28-5.49 U \text {. }
$$

\section{Locomotor energetics}

During terrestrial locomotion the mass-specific metabolic rate of the platypus $\left(\dot{V}_{\mathrm{O}_{2}}\right)$ was linearly dependent on speed $(U)$ (Fig. 4 ; Table $1 ; t=3.63 ; P<0.003$ ). The equation describing the relationship is:

$$
\dot{V}_{\mathrm{O}_{2}}=0.45+1.02 U,
$$

where $\dot{\mathrm{O}}_{2}$ has units of $\mathrm{mlO}_{2} \mathrm{~g}^{-1} \mathrm{~h}^{-1}$ and $U$ is in $\mathrm{m} \mathrm{s}^{-1}$. Over a range of speeds from 0.19 to $1.08 \mathrm{~m} \mathrm{~s}^{-1}, \dot{V}_{\mathrm{O}_{2}}$ showed a 2.4-fold increase. The mean value of $\dot{V}_{\mathrm{O}_{2}}$ for the highest speeds at which the animals would walk was 4.3 times the measured standard
Fig. 2. Duty factor $(D)$ and the percentage of time that the forefoot follows an ipsilateral hindfoot movement $\left(P T_{\mathrm{f}-\mathrm{h}}\right)$ plotted against walking speed. Data for the duty factor are indicated by filled circles; data for $P T_{\mathrm{f}-\mathrm{h}}$ are indicated by open circles. Regression lines were fitted by least-squares regression according to equations 3 and 4 in the text.

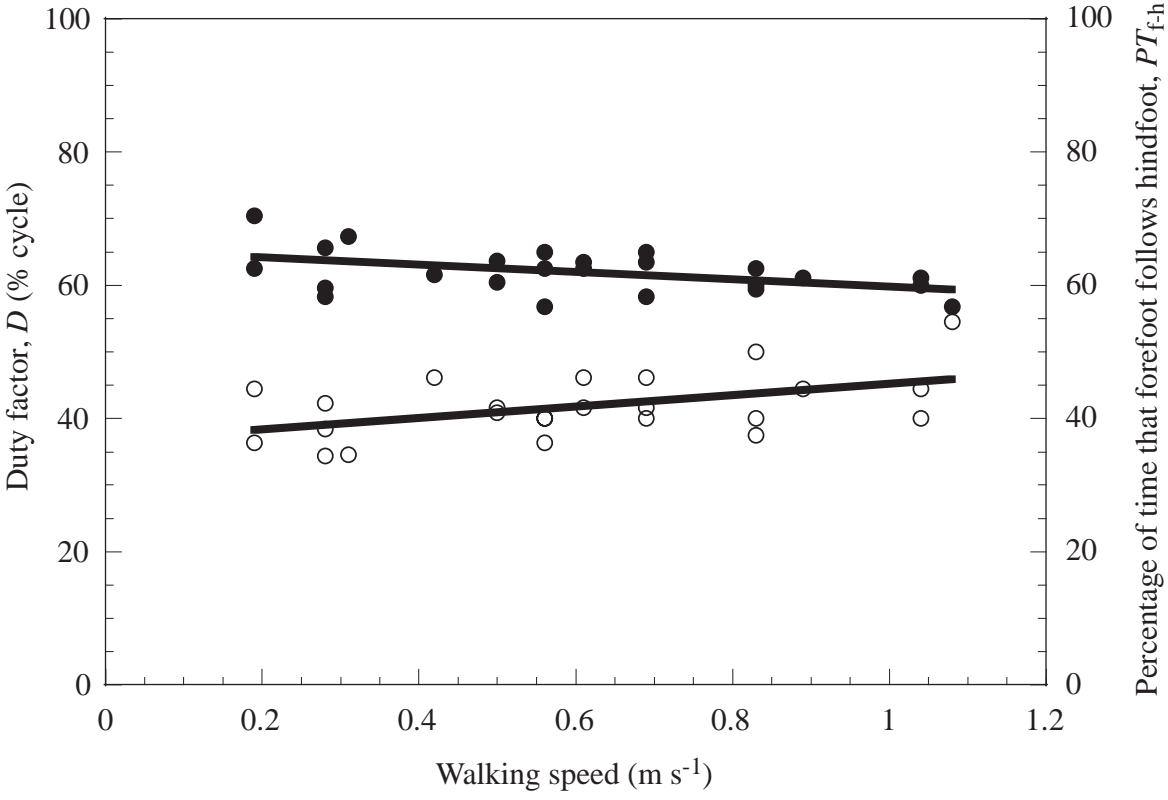




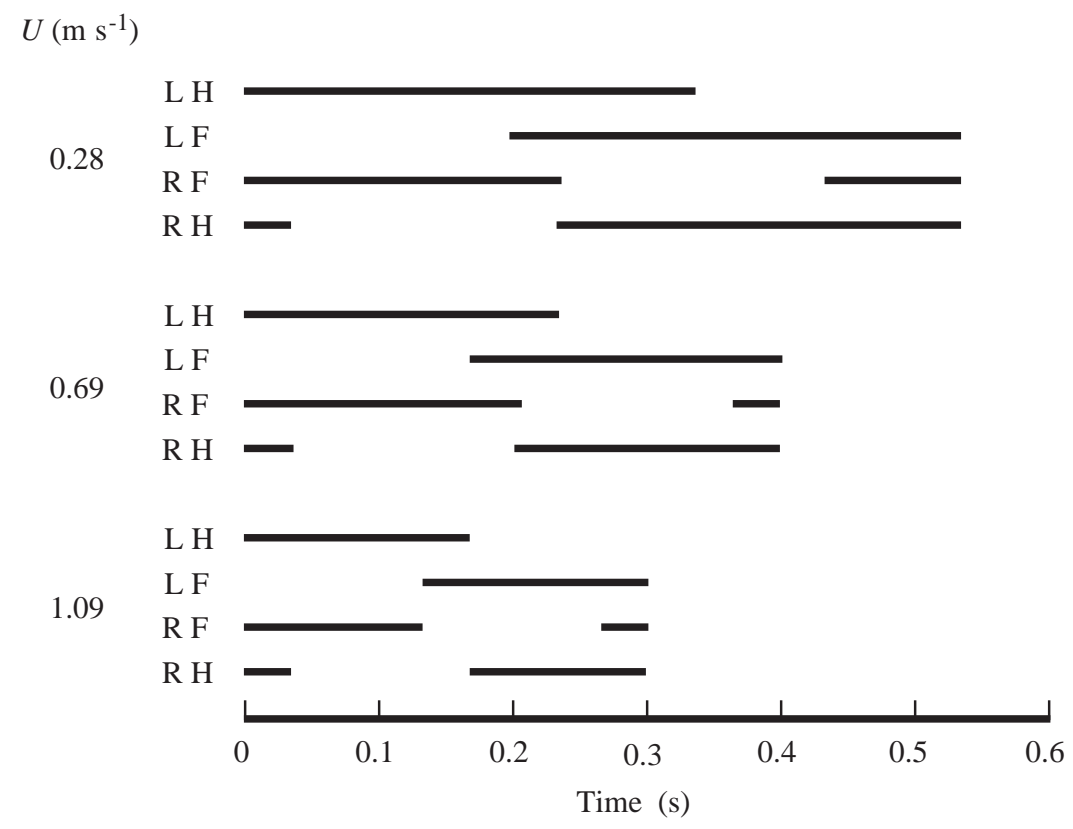

metabolic rate of platypuses over a mass range of $1.01-1.62 \mathrm{~kg}$ (Dawson et al., 1979).

\section{Cost of transport}

The cost of transport (COT) decreased curvilinearly towards an asymptotic value with increasing $U$ (Fig. 5). The equation describing the relationship was:

$$
C O T=0.75 U^{0.63},
$$

where $C O T$ has the dimensionless units $\mathrm{J} \mathrm{N}^{-1} \mathrm{~m}^{-1}$ and $U$ is the velocity in $\mathrm{m} \mathrm{s}^{-1}$. The relationship between $C O T$ and $U$ was statistically significant (Table $1 ; t=-3.93 ; P<0.002$ ). The lowest mean value for cost of transport $\left(C O T_{\min }\right)$ based on the prediction of equation 6 was 0.79 at $U=1.08 \mathrm{~m} \mathrm{~s}^{-1}$.

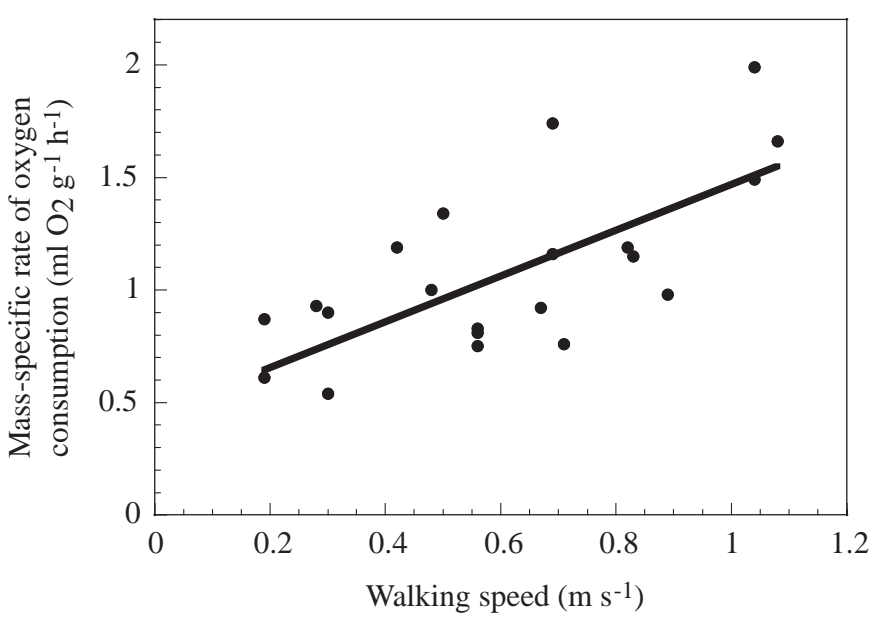

Fig. 4. Mass-specific rate of oxygen consumption of platypuses as a function of walking speed. The line was fitted by least-squares regression according to equation 5 in the text.

\section{Discussion \\ Limb specialization and energetics}

The platypus Ornithorhynchus anatinus possesses many features characteristic of early mammals with a terrestrial form of locomotion that is considered primitive (Pridmore, 1985). The platypus has a sprawling stance with the humerus oriented parallel with the ground (Howell, 1937; Howell, 1965; Eaton, 1962; Gray, 1968). When walking slowly, the ventral surface of the body rubs against the ground, but at higher speeds the body is carried slightly above the ground (Burrell, 1927; Pridmore, 1985). Although the stance and locomotor movements of the platypus have been viewed as similar to those of reptiles, representing the locomotor condition of ancestral mammals (Bakker, 1971; Reilly and Elias, 1998), cinematographic and cineradiographic analysis indicated that the limb motions of the platypus were considerably modified from the ancestral condition (Pridmore, 1985).

Despite primitive aspects of the platypus (e.g. egg laying, the presence of an interclavicle bone in the pectoral girdle), this mammal demonstrates highly specialized habits and anatomical structures that are adapted for a semi-aquatic existence (Burrell, 1927; Howell, 1937; Griffiths, 1988; Fish et al., 1997). The anatomical features include a dense, nonwettable fur and webbed feet. The forefeet are particularly interesting in that only they are used during swimming, while the hind feet are immobile and held against the body (Howell, 1937; Grant, 1989). The platypus swims with its forefeet extended laterally from body using an alternate rowing motion (Howell, 1937; Grant, 1989; Fish et al., 1997). This is a unique swimming mode not found in other semi-aquatic mammals (Howell, 1930; Fish, 1993; Fish, 1996). The lateral orientation of the humerus permits the rowing action for propulsion. To increase the area of the propulsive foot to affect a large mass of water, the foot is broadly webbed. The webbing extends well 


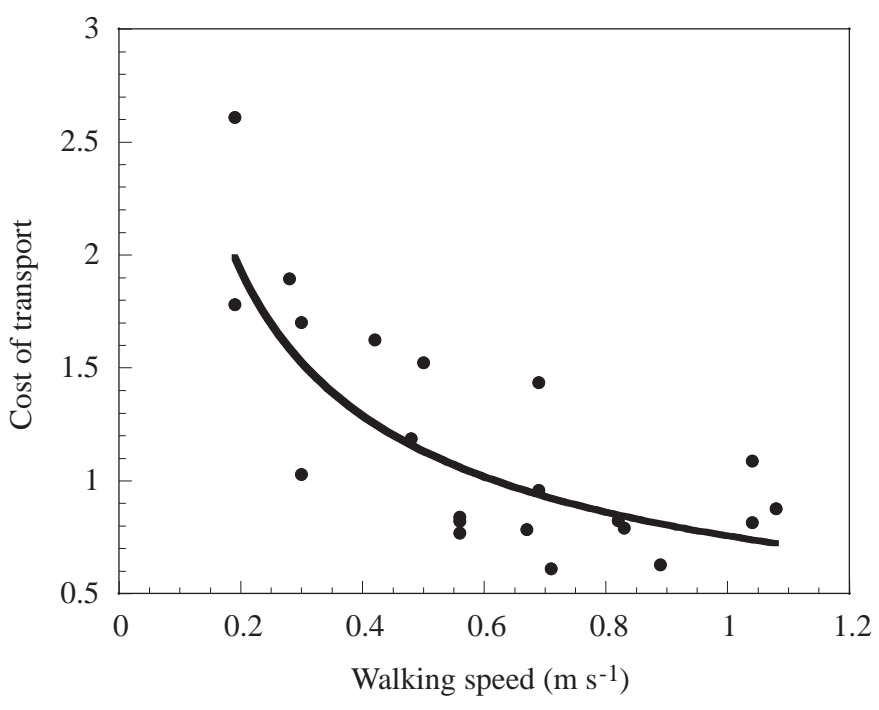

Fig. 5. Dimensionless cost of transport (COT) plotted against speed of walking. The curvilinear relationship (solid line) was calculated according to equation 6 in the text.

beyond the distal ends of the digits and claws. Because of the extensive structure of the webbing, terrestrial locomotion is accomplished by knuckle-walking (Burrell, 1927).

The present study predicted that limb specializations associated with the semi-aquatic existence of the platypus would constrain the animal's ability to locomote rapidly on land. For the range of speeds tested, the platypus never demonstrated a gait in which only two feet contacted the ground over a complete stride cycle: the platypus were unable to trot. A trot is a symmetrical gait in which the fore and hind foot on opposite sides of the body contact the ground simultaneously and alternate with the other pair of feet (Hildebrand, 1976; Hildebrand, 1989). Trotting is used at moderate speeds by terrestrial mammals. The gaits displayed by the platypus (single foot in lateral sequence, diagonal couplet in a lateral sequence) are the same gaits favoured by many stocky, shorter-legged mammals, such as the hedgehog, tenrec, beaver and marmot (Hildebrand, 1976; Hildebrand, 1989). These gaits provide a high level of stability for walking when the body is supported by either two or three legs.

The linear increase in metabolic rate with increasing speed for the platypus is similar to the trend observed for terrestrial mammals (Taylor et al., 1970). However, the slope of the increase in metabolic rate with increasing locomotor speed was higher than for similarly sized mammals including the echidna Tachyglossus aculeatus (Edmeades and Baudinette, 1975; Taylor et al., 1982). The metabolic rate of the platypus was lower than that of a similarly sized eutherian mammal. Despite the derived locomotor pattern of the platypus, a lowered metabolic rate was not unexpected. Monotremes display lower resting metabolic rates than other mammals (Martin, 1902; Smyth, 1973). The resting rate for the platypus is $8 \%$ lower than that of marsupials and $35 \%$ lower than that of eutherians (Dawson and Hulbert, 1970). In examining the energetics of terrestrial locomotion in the echidna, Edmeades and Baudinette
(Edmeades and Baudinette, 1975) found that its metabolic rate was lower than that of other mammals. The lower rate was considered to be a consequence of the comparatively low resting metabolic rate of the echidna, despite its possession of heavy modified limbs adapted for burrowing.

Because of the low active metabolic rate of monotremes, comparisons of locomotor effort made by examining the minimum cost of transport (COT $\min$ ) indicate lower values than that typical of a mammal of equivalent body size. The echidna has a lower cost of transport than predicted for other mammals (Edmeades and Baudinette, 1975). Thus, the total energy requirement to travel an equivalent distance was smaller for the monotreme. The relationship between $C O T_{\min }$ and body mass $\left(M_{\mathrm{b}}\right.$; in $\left.\mathrm{kg}\right)$ for terrestrial locomotion by eutherian mammals (Williams, 1999) is:

$$
C O T_{\min }=\left(10.7 M_{\mathrm{b}^{-0.32}}\right) / 9.8 .
$$

For a platypus with a mean body mass of $1.395 \mathrm{~kg}$, the predicted $C O T_{\min }$ is 0.98 which is 1.24 times greater than the measured mean value. The amount of energy expended increases directly with the work performed, so the metabolic increment above resting metabolic rate will increase in direct proportion with the speed of an animal. Therefore, subtraction of the resting costs from the active cost of locomotion will give a net $C O T_{\min }$ that can provide an equitable comparison of locomotor effort regardless of taxonomic status.

Taylor et al. (Taylor et al., 1970) determined net $C O T_{\min }$ using the slope of the relationship between metabolic rate and speed for terrestrial locomotion by mammals. Net $C O T_{\min }$ was associated with body mass according to the equation:

$$
M_{\text {terr }}=8.46 M_{\mathrm{b}}{ }^{-0.40},
$$

where $M_{\text {terr }}$ is net $C O T_{\min }$ expressed in $\mathrm{ml} \mathrm{O}_{2} \mathrm{~g}^{-1} \mathrm{~km}^{-1}$ and $M_{\mathrm{b}}$ is the body mass in $\mathrm{g}$. Net $C O T_{\min }$ for a mammal of equivalent size to a $1.395 \mathrm{~kg}$ platypus is predicted to be $0.467 \mathrm{ml} \mathrm{O}_{2} \mathrm{~g}^{-1} \mathrm{~km}^{-1}$. This is only $68.3 \%$ of the net cost for the platypus during terrestrial locomotion, when a resting metabolic rate of $0.256 \mathrm{ml} \mathrm{O}_{2} \mathrm{~g}^{-1} \mathrm{~h}^{-1}$ (Smyth, 1973) was subtracted from the metabolic rate of a platypus travelling at $1.08 \mathrm{~m} \mathrm{~s}^{-1}$. The higher cost of terrestrial locomotion by the platypus compared with eutherian mammals may be the result of a number of factors, including the sprawled stance and knuckle-walking, which are consequences of its aquatically adapted morphology. A sprawling stance would limit the ability of the animal to conserve energy by using elastic mechanisms and pendular movements (Cavagna et al., 1977; Heglund et al., 1982; Alexander, 1991).

\section{Comparison of walking and swimming energetics}

Fish and Baudinette (Fish and Baudinette, 1999) postulated that there were morphological and physiological trade-offs associated with the conflicting demands of semi-aquatic mammals operating in both terrestrial and aquatic regimes. Williams (Williams, 1999) argued that specialist mammals, both aquatic and terrestrial, have reached energetic optima with regard to locomotor costs. Semi-aquatic mammals incur 
Fig. 6. Relative cost of transport for terrestrial locomotion (white columns) and swimming (black columns) of the platypus Ornithorhynchus anatinus (this study; Fish et al., 1997), human (Holmér and Åstrand, 1972; DiPrampero, 1986), mink Mustela vison (Williams, 1983a; Williams, 1983b), penguin Eudyptula minor (Pinshow et al., 1977; Baudinette and Gill, 1985), water rat Hydromys chrysogaster (Fish and Baudinette, 1999) and white rat Rattus norvegicus (Taylor et al., 1970; Benthem et al., 1994). With increasing aquatic adaptation, there is a reversal in the magnitude of the cost of transport between aquatic and terrestrial locomotion.

metabolic costs for aquatic and terrestrial locomotion that are higher than those of the specialists (Fish and Baudinette, 1999; Williams, 1999). The higher metabolic costs for swimming by semi-aquatic mammals are due to incomplete streamlining of the body, the use of an inefficient, drag-based paddle propulsion and increased energy losses from wave drag as a result of swimming at the air/water interface (Howell, 1930; Hertel, 1966; Fish, 1992; Fish, 1993; Fish, 1996; Williams, 1983a; Williams, 1989; Williams, 1999; Baudinette and Gill, 1985). However, the platypus differs from other semi-aquatic mammals by swimming submerged and using a rowing stroke (Howell, 1930; Howell, 1937; Kruuk, 1993; Evans et al., 1994; Fish et al., 1997). As a result, a swimming platypus uses energy at a low rate similar to that of a highly specialized aquatic mammal (Fish et al., 1997).

The $C O T_{\min }$ for walking by the platypus is 2.1 times greater than that for swimming (Fig. 6). Fish and Baudinette (Fish and Baudinette, 1999) compared the $C O T_{\min }$ for terrestrial and aquatic locomotion in a variety of animals. The resting metabolic rate was assumed to be constant for each animal, regardless of locomotor mode, so differences in $C O T_{\min }$ between terrestrial and aquatic locomotion were considered to be a reflection of the locomotor effort. The difference in $C O T_{\min }$ between movement on land and in water for aquatic specialists was opposite to the difference exhibited by terrestrial animals. The aquatic penguin has a $C O T_{\min }$ for terrestrial locomotion that is 1.8 times greater than for swimming (Pinshow et al., 1977; Baudinette and Gill, 1985). For terrestrial animals, the opposite trend is evident because these animals are relatively poor swimmers. Humans, Norway rats and mink have swimming costs that are greater than their costs of terrestrial locomotion by 3.9-, 1.8- and 2.7-fold, respectively (Taylor et al., 1970; Holmér and Åstrand, 1972; Williams, 1983a; Williams, 1983b; DiPrampero, 1986; Benthem et al., 1994). The semi-aquatic Australian water rat (Hydromys

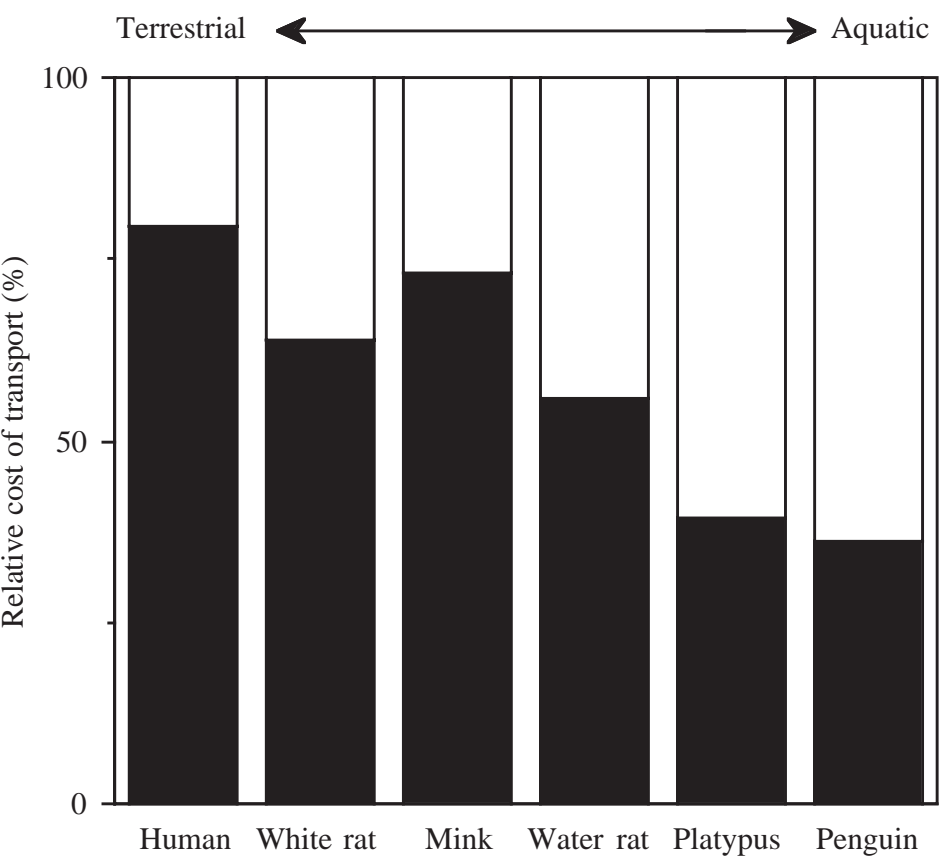

chrysogaster) is intermediate between terrestrial and aquatic specialists, with swimming costs only 1.25 times greater than its $C O T_{\text {min }}$ for terrestrial locomotion (Fish and Baudinette, 1999).

The difference in locomotor costs for terrestrial locomotion and swimming in the platypus indicates the development of aquatic specializations that permit efficient locomotion in water. However, the platypus pays a price with regard to its energetic expenditure for terrestrial locomotion. Although its sprawled stance and extensive webbing work effectively for aquatic propulsion, they may impede locomotion on land and increase the cost of terrestrial locomotion.

We wish to express our appreciation to Dr Katherine Handasyde of the Department of Zoology, University of Melbourne, to Paul Wiggins, Kristen Munro and Julie Smith for assistance in the collection of animals and to the Victorian Fisheries Research Institute (Snobs Creek) for the use of facilities and equipment. Experiments were conducted under appropriate AEC approval (La Trobe University AEC99/42), and platypuses were collected under Victorian Department of Conservation and Natural Resources permits (10000830 and RP594). Appreciation is expressed to G. W. Fairchild for statistical assistance and two anonymous reviewers for their comments on the manuscript. This work was supported in part by ARC grants to R.V.B. and P.B.F. and a West Chester University College of Arts and Sciences Support and Development Award to F.E.F.

\section{References}

Alexander, R. McN. (1991). Energy-saving mechanisms in walking and running. J. Exp. Biol. 160, 55-69.

Bakker, R. T. (1971). Dinosaur physiology and the origin of mammals. Evolution 25, 636-658.

Baudinette, R. V. and Gill, P. (1985). The energetics of 'flying' and 
'paddling' in water; locomotion in penguins and ducks. J. Comp. Physiol. 155, 373-380.

Baudinette, R. V., Snyder, R. V. and Frappell, P. B. (1992). Energetic cost of locomotion in the tammar wallaby. Am. J. Physiol. 262, R771-R778.

Benthem, L., Bolhuis, J. W., van der Leest, J., Steffens, A. B., Zock, J. P. and Zijlstra, W. G. (1994). Methods for measurement of energy expenditure and substrate concentrations in swimming rats. Physiol. Behav. 56, 151-159.

Burrell, H. (1927). The Platypus. Sydney: Angus \& Robertson.

Cavagna, G. A., Heglund, N. C. and Taylor, C. R. (1977). Mechanical work in terrestrial locomotion: two basic mechanisms for minimizing energy expenditure. Am. J. Physiol. 233, R243-R261.

Dawson, T. J., Grant, T. R. and Fanning, D. (1979). Standard metabolism of monotremes and the evolution of homeothermy. Aust. J. Zool. 27, 511-515.

Dawson, T. J. and Hulbert, A. J. (1970). Standard metabolism, body temperature and surface areas of Australian marsupials. Am. J. Physiol. 218, 1233-1238.

DiPrampero, P. E. (1986). The energy cost of human locomotion on land and in water. Int. J. Sports Med. 7, 55-72.

Eaton, T. H. (1962). Adaptive features of the forelimb in primitive tetrapods and mammals. Am. Zool. 2, 157-160.

Edmeades, R. and Baudinette, R. V. (1975). Energetics of locomotion in a monotreme, the echidna Tachyglossus aculeatus. Experimentia 31, 935-936.

Evans, B. K., Jones, D. R., Baldwin, J. and Gabbott, G. R. J. (1994). Diving ability of the platypus. Aust. J. Zool. 42, 17-27.

Fish, F. E. (1992). Aquatic locomotion. In Mammalian Energetics: Interdisciplinary Views of Metabolism and Reproduction (ed. T. E. Tomasi and T. H. Horton), pp. 34-63. Ithaca, NY: Cornell University Press.

Fish, F. E. (1993). Influence of hydrodynamic design and propulsive mode on mammalian swimming energetics. Aust. J. Zool. 42, 79-101.

Fish, F. E. (1996). Transitions from drag-based to lift-based propulsion in mammalian swimming. Am. Zool. 36, 628-641.

Fish, F. E. and Baudinette, R. V. (1999). Energetics of locomotion by the Australian water rat (Hydromys chrysogaster): a comparison of swimming and running in a semi-aquatic mammal. J. Exp. Biol. 202, 353-363.

Fish, F. E., Baudinette, R. V., Frappell, P. B. and Sarre, M. P. (1997). Energetics of swimming by the platypus Ornithorhynchus anatinus: metabolic effort associated with rowing. J. Exp. Biol. 200, 2647-2652.

Frappell, P. B., Saiki, C. and Mortola, J. P. (1991). Metabolism during normoxia, hypoxia and recovery in the newborn kitten. Respir. Physiol. 86, 115-124.

Grant, T. R. (1989). The Platypus: A Unique Mammal. Sydney: University of New South Wales Press.

Grant, T. R. and Dawson, T. J. (1978). Temperature regulation in the platypus, Ornithorhynchus anatinus: Production and loss of metabolic heat in air and water. Physiol. Zool. 51, 315-332.

Gray, J. (1968). Animal Locomotion. London: Weidenfeld and Nicolson.

Griffiths, M. (1988). The platypus. Scient. Am. 258, 84-91.

Heglund, N. C., Fedak, M. A., Taylor, C. R. and Cavagna, G. A. (1982). Energetics and mechanics of terrestrial locomotion. IV. Total mechanical energy changes as a function of speed and body size in birds and mammals. J. Exp. Biol. 97, 57-66.

Hertel, H. (1966). Structure, Form and Movement. New York: Rheinhold.
Hildebrand, M. (1976). Analysis of tetrapod gaits: general considerations and symmetrical gaits. In Neural Control of Locomotion (ed. R. M. Herman, S. Grillner, P. S. G. Stein and D. G. Stuart), pp. 203-236. New York: Plenum Press.

Hildebrand, M. (1980). The adaptive significance of tetrapod gait selection. Am. Zool. 20, 255-267.

Hildebrand, M. (1989). The quadrupedal gaits of vertebrates. Bioscience 39, 766-775.

Holmér, I. and Åstrand, P.-O. (1972). Swimming training and maximal oxygen uptake. J. Appl. Physiol. 33, 510-513.

Howell, A. B. (1930). Aquatic Mammals. Springfield, IL: Charles C. Thomas.

Howell, A. B. (1937). The swimming mechanism of the platypus. $J$. Mammal. 18, 217-222.

Howell, A. B. (1965). Speed in Animals. New York: Hafner.

Kruuk, H. (1993). The diving behaviour of the platypus (Ornithorhynchus anatinus) in waters with different trophic status. J. Appl. Ecol. 30, 592-598.

Martin, C. J. (1902). Thermal regulation and respiration exchange in monotremes and marsupials: a study in the development of homeothermism. Phil. Trans. R. Soc. Lond. B 195, 1-37.

McDonald, I. R., Handasyde, K. A. and Evans, B. K. (1992). Adrenal function in the platypus. In Platypus and Echidnas (ed. M. L. Augee), pp. 127-133. Sydney: Royal Zoological Society of New South Wales.

Pinshow, B., Fedak, M. A. and Schmidt-Nielsen, K. (1977). Terrestrial locomotion in penguins: It costs more to waddle. Science 195, 592-594.

Pridmore, P. A. (1985). Terrestrial locomotion in monotremes (Mammalia: Monotremata). J. Zool., Lond. 205, 53-73.

Reilly, S. M. and Elias, J. A. (1998). Locomotion in Alligator mississippiensis: kinematic effects of speed and posture and their relevance to the sprawling-to-erect paradigm. J. Exp. Biol. 201, 2559-2574.

Smyth, D. (1973). Temperature regulation in the platypus, Ornithorhynchus anatinus (Shaw). Comp. Biochem. Physiol. 45, 705-716.

Taylor, C. R., Heglund, N. C. and Maloiy, G. M. O. (1982). Energetics and mechanics of terrestrial locomotion. I. Metabolic energy consumption as a function of speed and body size in birds and mammals. J. Exp. Biol. 97, 1-21.

Taylor, C. R., Schmidt-Nielsen, K. and Raab, J. L. (1970). Scaling of the energetic cost of running to body size in mammals. Am. J. Physiol. 219, 1104-1107.

Tucker, V. A. (1970). Energetic cost of locomotion in animals. Comp. Biochem. Physiol. 34, 841-846.

Videler, J. J. and Nolet, B. A. (1990). Cost of swimming measured at optimum speed: Scale effects, differences between swimming styles, taxonomic groups and submerged and surface swimming. Comp. Biochem. Physiol. 97A, 91-99.

Williams, T. M. (1983a). Locomotion in the North American mink, a semi-aquatic mammal. I. Swimming energetics and body drag. $J$. Exp. Biol. 103, 155-168.

Williams, T. M. (1983b). Locomotion in the North American mink, a semi-aquatic mammal. II. The effect of an elongate body of running energetics and gait patterns. J. Exp. Biol. 105, 283-295.

Williams, T. M. (1989). Swimming by sea otters: adaptations for low energetic cost locomotion. J. Comp. Physiol. A 164, 815-824.

Williams, T. M. (1999). The evolution of cost efficient swimming in marine mammals: limits to energetic optimization. Phil. Trans. $R$. Soc. Lond. B 354, 193-201. 